\title{
responses
}

\section{John Nolt's Inductive Reasoning Test}

\author{
Howard Kahane
}

\section{University of Maryland Baltimore County}

It seems to me that John Nolt is right in his remarks concerning teaching informal logic students about deductive validity/invalidity through the notions of valid and invalid deductive forms: that doesn't work very well. And I think he's right that a better way to teach about deductive validity is to get students to "regard an argument as valid just in case the simultaneous truth of its premises and falsity of its conclusion cannot coherently be conceived." (I intend to make the 5th edition of my own text conform to his insight.)

But Nolt's ideas about assessing the various strengths of inductive reasonings, while very interesting, and effective for some kinds of inductive arguments, do not work correctly in general.1

Nolt illustrates his theory by a one premise argument. Roughly, his method is to take the percentage of logically possible worlds in which the premise is true and the conclusion also is true, compare this to all the possible worlds in which the premise is true, and consider the percentage obtained in this way to be the strength of the inductive reasoning. This works all right for the type of arguments he considers, for instance the argument:

\section{Everyone believes that Neil Armstrong walked on} the moon.

$\therefore$ Neil Armstrong walked on the moon.

The percentage of worlds in which the premise is true and conclusion true compared to all the possible worlds in which the premise is true is very small, so that on Nolt's theory the inference is weak, which conforms to our intuitions on the matter.
But consider another sort of inductive reasoning:

All crows examined so far have been black.

- All crows whatsoever are black.

Using Nolt's possible worlds method, we must conclude that this inference is quite weak, since its conclusion is false in a large percentage of the logically possible worlds in which its premise is true. Yet intuitively, the inference is quite strong. (How strong depends on things like the size of our sample, etc., but not on the number of logically possible worlds that are one way or another.)

Note

${ }^{1}$ The reason is related, interestingly, to disputes over induction years ago between Rudolf Carnap, whose inductive theory is a range theory à la Wittgenstein, and Hans Reichenbach, who rejected such theories as a priori. But a discussion of this point is not relevant to this note. $\square$

Dr. Howard Kahane, Department of Philosophy, University of Maryland - Baltimore County, Baltimore, MD 21228 


\title{
Degrees of Validity and Ratios of Conceivable Worlds
}

\author{
Stephen N. Thomas
}

\section{University of South Florida}

Professor Nolt interested me with his fascinating article, "Possible Worlds and Imagination in Informal Logic," a somewhat similar "possible worlds" approach in attempting to formulate a unitary definition of the concept of "validity" applicable to all inferences in natural language. However, I was dissuaded from such an approach by certain difficulties. If I describe some of these, perhaps Professor Nolt will be able to explain to us how these problems are avoided on his approach.

\section{I}

Nolt proposes the following definition, or procedure, for determining the degree to which reasons support a conclusion in nonconclusive ("inductive") as well as conclusive inference:

\footnotetext{
... The fundamental idea is to measure strength of reasoning by the proportion of conceivable worlds in which the conclusion is true among worlds in which the premises are true. If this proportion is $100 \%$, the argument is (deductively) valid. If it is $0 \%$, the premises imply the negation of the conclusion. And there are infinitely many degrees of strength between these two extremes.2
}

He tacitly assumes that the various "possible worlds" are all equally probable, so that only the ratio of their numbers need be considered to evaluate the degree of support of inferences. Nolt claims "that the framework of possible worlds provides a unified scheme for defining and interrelating, not only the usual all-or-nothing logical concepts, but also those that admit of degrees," 3 and he implies that the concept of "degree of validity" (or "degree of support," if one prefers) in natural logic might be among these, at least to an approximation 4
The main problem with Nolt's approach is that it seems to be strictly fallacious: although, when applied to some examples, it leads to evaluations that are correct and identical to the evaluations obtained by the methods of natural logic, in infinitely many other instances, it appears to lead to evaluations that are wildly inaccurate.

II

In some cases, Nolt's approach seems to lead to evaluations of the strength of inferences that are far too high. For convenience, consider the following simple, concocted example:

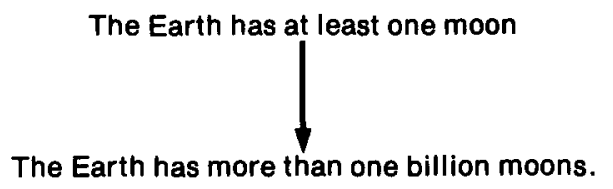

Intuitively, the premise here gives little or no support to this conclusion. What evaluation does Nolt's approach yield?

To apply Nolt's evaluative procedure, we must find or estimate, the "proportion of conceivable worlds in which the conclusion is true among worlds in which the premises are true." The conceivable worlds in which the premise is true would be all the conceivable worlds in which the Earth has one or more moons. Now in what proportion of these is the conclusion true? Remember that in Nolt's approach, each conceivable world counts equally; they are not weighted acccording to their relative probabilities. Following the line taken in his illustrations, we would consider the conceivable numbers of moons that the Earth might have, and ask for what proportion of these the conclusion would be true. The con- 
clusion would be true for all numbers of moons greater than one billion; it would be false for all numbers of moons equal to one billion or less. Now what is the ratio of the number of integers greater than one billion to the number equal or less than one billion? There are infinitely many integers greater than one billion, and a finite number equal to or less than one billion, so it is not exactly clear how this question is to be answered, but the ratio would seem to be very high. In almost $100 \%$ of the conceivable worlds in which the premise is true, the conclusion also is true. So evidently, this very weak inference would rate a "very strong" (almost deductively valid) rating, according to Nolt's method or procedure.

This appears to be a case in which Nolt's approach leads to an evaluation that is far too high. Obviously, infinitely many similar counter-examples could be constructed in which Nolt's approach also leads to ratings that are far too high. So the first problem is that Nolt's method fallaciously gives high ratings to intinitely many weak or nil steps of inference.

\section{III}

The second problem is that Nolt's account fails to generate accurate evaluations even in what one would expect would be its most favorable class of cases, namely, statistical generalizations from samplings that can be analyzed in terms of ratios of numbers of equally possible cases. Consider balls drawn from an urn at random. Suppose there are fifty balls in the urn, and that the first forty-nine, drawn at random, all have been blue. Normally we would say that the following reasoning deserves a rating of "strong":

There were 50

balls in the urn.
The first 49 , all drawn at random, have been blue.

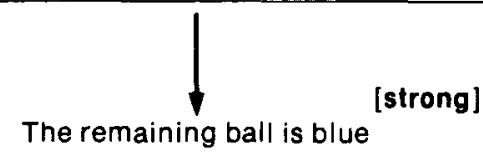

If one calculates the probability that the remaining ball is blue given that the first forty-nine drawn at random have been blue, the probability is well in excess of $80 \%$. How does the strength rate on an analysis in accordance with Nolt's approach?

On Nolt's approach, one would "measure strength of reasoning by the proportion of conceivable worlds in which the conclusion is true among worlds in which the premises are true." The conceivable worlds in which the premises are true presumably would be the conceivable worlds in which we had drawn forty-nine balls at random from an urn containing fifty, and found that all forty-nine were blue. Now, in what proportion of these is the conclusion true? Well, there is the possible world in which the first forty-nine balls were blue and the last ball is blue too; this is the possible world in which the conclusion is true. How many possible worlds are there in which premises are true, but the conclusion is false? A small problem arises here: Are we to count the possible worlds in which the last ball is white, say, as distinct from the possible worlds in which the last ball is red, green, black, etc., or are we supposed to lump all the non-blue cases together as just one possible world, the possible world (worlds?) in which the last ball is nonblue? The former course seems more reasonable, since all these various ways in which the last ball could be non-blue seem to be distinct possible worlds, and it does not seem reasonable to say that the probability that a given object is blue, rather than any other color, is $50 \%$. How many non-blue colors are there? Again it is difficult to say, but an examination of sample books of color chips from paint manufacturing companies indicates that the number is very large, certainly in excess, say, of 300 . So, among the possible worlds in which the premises are true, there is one possible world in which the conclusion is true, and more than 300 in which it is false. We thus arrive at the evaluation that the strength of the inference is less than $1 \%$, very weak indeed. This seems clearly erroneous. On the other approach, if we counted all the possible worlds with a non-blue last ball as just one possible world, the ratio would become $50 \%$, still far less than standard statistical approaches calculate, and far less than the evaluation reached by the methods of natural logic, and far less than our rational intuitions would indicate.

Here, then, is a case typical of another infinite set of cases, in which Nolt's "conceivable worlds" approach again appears to be fallacious, this time because it generates evaluations that are inaccurate through being far too low-or have 1 missed something?

\section{IV}

How are arguments in which reasons give "nil" support to their conclusion evaluated on Nolt's model? Nolt says that if the proportion of conceivable worlds in which the conclusion is true among worlds in which the premises are true "is $0 \%$, the premises imply the negation of the conclusion." This could not be the same as "nil" or " $0 \%$ " support as represented in the natural-logic model, because reasoning in which the premises give no support to the conclusion need not be arguments in which the conclusion is true in none of the possible worlds in which the premises are true. Consider, for example: 
Some roses are red. $+\quad$ Some violets are blue

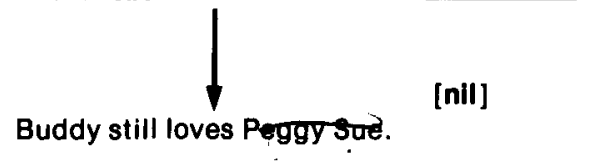

The validity of this reasoning is "nil" or " $0 \%$ " on the natural-logic approach, because the truth of the premises does nothing to make the truth of the conclusion likely. But the proportion of conceivable worlds in which the conclusion is true among the totality of conceivable worlds in which the premises are true obviously is not $0 \%$, since in some conceivable worlds where some roses are red and some violets are blue, Buddy does still love Peggy Sue.

Since generally in such cases, the proportion or ratio is greater than $0 \%$, does this mean that on Nolt's model, the only cases in which reasons give no support to a conclusion (a conclusion that is a contingent statement) are the cases in which they entail its negation? Does Nolt's model conflate providing no support for a conclusion with implying its negation? There seems to be no place in Nolt's model for the situation in which the premises do not imply the negation of the conclusion, but the degree of validity (or degree of support, or strength) of the inference is $0 \%$ or nil.

What ratio of conceivable worlds in which the reasons are true to conceivable worlds in which the conclusion is true would correspond to the reasons and conclusion being completely irrelevant to each other as far as the relation of logical support or entailment is concerned? Here again the neo-extensionalist "conceivable worlds" approach seems to fail really to get at what makes for the "connectedness" between reasons and conclusions in a valid inference (or the lack thereof).

\section{V}

A further problem is that another argument similar to the one about Buddy above except with the conclusion instead, "Buddy does not still love Peggy Sue" an inference that again should rate close to a "nil" would rate almost $100 \%$ (somewhere in the range "strong to deductively valid") on Nolt's model, since the number of conceivable worlds in which Buddy does not still love Peggy Sue is so much larger than the number in which Buddy does still love Peggy Sue. In fact, Nolt's model apparently strictly entails that if reasons $\mathbf{R}_{1}, \mathbf{R}_{\mathbf{2}}, \ldots, \mathbf{R}_{\mathbf{n}}$ give $\mathbf{P} \%$ support to conclusion $\mathbf{C}$, then the same set of reasons should give (100 minus P)\% support to a conclusion that is the negation of conclusion $\mathbf{C}$ (since, if $\mathbf{P} \%$ is the percentage of conceivable worlds in which $\mathbf{C}$ is true (of the worlds in which the reasons are true), then the percentage of those same worlds in which $\mathbf{C}$ is false would necessarily be the complement of $\mathbf{P} \%$, namely $100 \%-\mathbf{P} \%$ ). So, for instance, Nolt's model appears strictly to imply that if certain reasons give $49 \%$ support to believing that a given conclusion is true, then the same reasons also give $57 \%$ support to its negation. This implication is, in general, of course, false. Examples are everywhere.

\section{VI}

Problems such as these (among others) dissuaded me from a "conceivable worlds" approach, and impelled me to the more radical, but far more accurate and much simpler, "natural-logic approach." I think that perhaps the fundamental problem with possible-worlds approaches is that they still are basically extensionalistic (or set-theoretic) accounts that involve impoverished models of the relations of semantic connectedness and entailment in natural languages.

Incidentally, the problem of representing the influence of "collateral information" in the naturallogic model (which Professor Nolt indicates contributed to the motivation for his alternative approach) will be addressed, and hopefully clarified, in the forthcoming third edition of Practical Reasoning in Natural Language. But I will remark that the relatively unrestricted, intentionally loose and free special notation of arrow diagrams and natural logic permit inferences to be evaluated in the context of a totality of presupposed collateral information that is allowed to remain tacitly understood in the background, without needing to be written down explicitly (unles a question arises about some part of it and circumstances require that some key additional assumptions be explicitly articulated, in which case they can be added to the diagram). Some contemporary philosophers of science and logicians have suggested that many scientific and other inferences in natural language ultimately presuppose much of the entire totality of the rest of our knowledge and beliefs as background assumptions, a totality so large that it would be hopeless ever to try actually to write it down. Since in practice, this totality of background information or assumptions generally exceeds the limit of what could ever be explicitly written down (the same problem arises on Nolt's approach), natural logic thus offers a realistic, genuinely workable method for evaluating such inferences-in contrast to the rigid traditional approaches that would (if anyone ever seriously attempted to apply them to actual cases) in effect, make the unrealistic, unsatisfiable, impossible demand that all collateral information and background assumptions be written down explicitly, along with the central core of premises, before the inference could be evaluated accurately. 
Notes

1 John Nolt, "Possible Worlds and Imagination in Informal Logic," Informal Logic, vi, 2 (1984), 14-17.

2 lbid., 15.

3lbid., 17

${ }^{4}$ On the natural-logic approach, the validity of an inference in a natural language is evaluated by asking the question: Is there any imaginable way (or "conceivable world," if one likes) in which the conclusion could be false, even if (or though) the reason(s) be true? If the answer to this question is "No," the inference is rated as "deductively valid." If the answer is "Yes," one next asks the question: How likely is (are) this (these) possibil-

\section{Reply to Englebretsen}

\section{James Freeman}

\section{Hunter College, CUNY}

I want to respond to certain criticisms George Englebretsen has expressed in "Freeman on Deduction/Induction" [2] of certain proposals I make for distinguishing deductive from inductive arguments, essentially in the last section of "Logical Form, Probability Interpretations, and the Inductive/ Deductive Distinction." [5]. Englebretsen seems dissatisfied, first, with the precedence criterion I consider that

$\left({ }^{*}\right)$ Explicit prima facie inductive or deductive indicators should take precedence over implicit indicators.

Second, he is dissatisfied with the lack of any theory to account for why an argument family should be either inductive or deductive. Let me reply to each of these in turn.

First, let me put the precedence criterion in the perspective of the entire paper. The purpose of the ities or conceivable world(s)? If all are highly unlikely, the degree of validity rates as "strong," and the inference still rates as "valid." But if some of these are real possibilities-states of affairs of the kind that may actually arise in the real world - then the inference rates as "invalid," and the degree of validity is classified as "moderate" or "weak," depending on the likelihood of these conceivable ways, or "nil" if the reason(s) give no support whatsoever to the conclusion. These ideas and procedures are introduced and explained in greater detail in Practical Reasoning in Natural Language (1973); Englewood Cliffs, N. J .: Prentice-Hall, 1981. [ ;

Dr. Stephen N. Thomas, Visiting Assistant Professor, Department of Philosophy, University of South Florida, Tampa, FL 33620. paper was to defend the inductive/deductive distinction, in particular to defend distinguishing arguments as being either inductive or deductive, against the claims of various persons, especially Perry Weddle in [10] and [11]. I proposed that judging whether an argument is inductive or deductive is akin to judging what is an overriding duty when confronted with one or more prima facie obligations which may or may not conflict. If the balance of inductive indicators outweighs the balance of deductive indicators, then the argument should be judged inductive. If the reverse, then deductive. As I see it, two of the strongest prima facie indicators are the explicit modal words like "possibly," "probably," "likely," on the inductive side, "necessarity," "must" on the deductive side, which I call explicit prima facie inductive (deductive) argument indicators; and the families, such as argument by analogy, causal argument, inductive generalization on the inductive side, and propositional argument, categorical syllogism on the deductive side to which an 
argument may belong. As I have said, traditionally arguments in the first group of families have been assessed by inductive standards, those in the second by deductive standards, and so membership in these families is a reason for saying that the argument is deductive or inductive. Since membership in a family does not make an explicit claim about the argument's being inductive or deductive, we regard it as an implicit prima facie inductive (deductive) argument indicator.

Trouble begins when our indicators conflict. Suppose we have an argument which, by virtue of its family membership, is clearly inductive, but which contains an explicit deductive indicator; or where the argument clearly belongs to a deductive family, but contains an explicit inductive indicator. Englebretsen's examples illustrate this clash nicely.

(1) Washington was rational.

Lincoln was rational.

Kennedy was rational.

So, all U.S. presidents must be rational.

(2) All men are rational.

All U.S. presidents are men.

So, probably all U.S. presidents are rational.

([2], p. 26) according to $\left({ }^{*}\right),(1)$ should be judged deductive, "must" taking precedence over the argument's being an inductive generalization; and (2) inductive, "probably" taking precedence over the argument's being a categorical syllogism.

Notice first that rejecting the proposed precedence rule, judging in this case (1) inductive and (2) deductive, would in no way affect the basic criterion that arguments should be judged inductive or deductive by whether the balance of indicators is deductive or inductive. The precedence rule is one way of determining that balance in certain cases. But, as pointed out in [5], p. 10, there can be disagreement over precedence rules and yet basic agreement on the criterion for distinguishing inductive from deductive arguments by the balance of indicators. Hence $\left({ }^{*}\right)$ is not part of my central thesis and can be modified or replaced without affecting my basic view.

In this connection, I should say there is something misleading in Englebretsen's saying I have proposed a "recipe" for distinguishing inductive from deductive arguments. As I understand it, a recipe is a procedure which can be applied rather mechanically to get a correct result. The thrust of my position in [5] is that decisions as to whether an argument is inductive or deductive are not mechanical, but require sensitivity to the argument and its context.

Englebretsen rejects the precedence rule, counting (1) as inductive and (2) as deductive. He offers justification for this in his suggestion for distinguishing inductive from deductive arguments. We shall examine this below. Englebretsen expects that most other teachers of logic would agree with his judgment about (1) and (2). This is an empirical claim, and I have no hard empirical data to either support or refute Englebretsen here. But I am not sure that all logic teachers would judge (1) and (2) this way. First, consider Irving M. Copi's definitions of "deductive argument" and "inductive argument" in the latest edition of Introduction to Logic:

We characterize a deductive argument as one whose
conclusion is claimed to follow from its premisses with
absolute necessity, this necessity not being a matter
of degree and not depending in any way upon whatever
else may be the case. And in sharp contrast we char-
acterize an inductive argument as one whose conclu-
sion is claimed to follow from its premisses only with
probability, this probability being a matter of degree
and dependent upon what else may be the case.

([1], p. 54) Again:

\begin{abstract}
Although every argument involves the claim that its premisses provide some grounds for the truth of its conclusion, only a deductive argument involves the claim that its premisses provide conclusive grounds. ... An inductive argument, on the other hand, involves the claim, not that its premisses give conclusive grounds for the truth of its conclusion, but only that they provide some support for it.
\end{abstract}

([1], p. 51) Now I do not know how Copi would react to Englebretsen's examples, but it seems to me that (1), by virtue of containing the modality "must" does claim that the conclusion follows with absolute necessity, and (2), by virtue of containing the modality "probably" claims that the conclusion follows only with probability. So, unless Copi has some other account of what it is for an argument to make these claims about how strongly the premises support the conclusion, to be consistent with his definition he should judge (1) deductive and (2) inductive. Of course, if it is a consequence of Copi's definition that (1) is deductive and (2) inductive, it is open to anyone who does not like this consequence to say "So much the worse for Copi's definition!" I present this merely as indirect empirical evidence that there are teachers of logic who would accept $\left({ }^{*}\right)$.

I think Copi is not the only logic teacher who would accept this precedence rule either. In [5], I point out that the precedence rule seems to capture the intuitions of people like Sam Fohr [4] and Fred Johnson [7] who want to take intentions of arguers seriously. But this is just additonal indirect empirical evidence that there are teachers of logic who accept $\left({ }^{*}\right)$. On the other hand, Englebretsen is not alone either in rejecting (*). As I point out in [5], David Hitchcock would surely oppose it. For all i know, there may be a case of what Robert Fogelin calls "deep disagreement" between these two 
groups of philosophers. What I have shown, contra Englebretsen, is that there may very well be two genuine groups of philosophers here, and so also genuine philosophical disagreement.

To try to develop a conclusive argument for one side or the other is beyond the scope of this reply, if indeed it can be done. What I should point out, however, is that Englebretsen is just plain wrong when he claims that I have given no argument for $\left({ }^{*}\right)$ in [5]. I have presented reasons for $\left({ }^{*}\right)$, although I have also been careful to point out that they are not conclusive or decisive. Besides pointing out that $\left({ }^{*}\right)$ captures the intuitions of certain philosophers, and that surely is a reason favoring a philosophical view, principle, or rule, 1 also offer the following reasoning which I am here adapting to Englebretsen's example and elaborating further. Suppose the person putting (1) forward really used "must" in the formal, technical, logical, or philosophical sense of this word to explicitly claim that the conclusion follows from the premises with absolute necessity. Indeed, we may expect this is the case with (1) since Englebretsen reports that it was given by a student in a logic class as an example of a deductive argument. But clearly there is something wrong with (1) as an example of a deductive argument, as Englebretsen agrees. What is wrong? (1) is a bad argument. It is bad precisely because it claims that its premises conclusively support the conclusion when in fact they do not - the argument is not deductively valid. In criticizing the argument, we take it as a deductive argument, criticize it as such, finding it to be an invalid deductive argument. But why did we take it as a deductive argument? Precisely because of the presence of the modality "must" in the argument. But why did we take that as the decisive factor in judging the argument deductive? We did so precisely because of $\left({ }^{*}\right) .\left({ }^{*}\right)$ then is an underlying assumption in our criticism of (1), that (1) is not a good argument, which it surely is not. $\left({ }^{*}\right)$ ultimately helps us to explain why this argument is bad. This fact, as suggested in [5], is a reason for $\left(^{*}\right)$. If a hypothesis (together with background information) yields correct explanations and predictions, those explanations and predictions constitute evidence for the hypothesis. Likewise, if a philosophical principle yields a certain judgment, say that an action is right or an argument bad, and that judgment is correct, that is evidence for the principle.

How would Englebretsen criticize (1)? I gather from [2] that Englebretson's criticism would be more linguistic rather than logical, pointing out that "must" is inappropriate in arguments like (1), which are inductive. As he says, "Indeed, our task as logic teachers is to bring $b^{\prime}$ 's [the student's] implicit claims and uses of illative signs into line" with traditional use. ([2], p. 27.) But this seems to me just wrong. Anyone who puts (1) forward as a good argument has made a logical mistake and has not just used the word "must" inappropriately.
His argument, not just its presentation, is faulty.

What about (2)? According to $\left({ }^{*}\right),(2)$ is to be counted inductive. Does this constitute a reason for or against $\left({ }^{*}\right)$ ? Now (2) is a distinctly odd argument. Unlike (1), which involves a logical mistake by claiming the premises give more support than they actually do, (2) claims they give less, which is not obviously wrong. To make a weaker claim when a stronger claim is warranted, unless one asserts that this is the most that can be claimed, is not wrong. Hence, with (2) we do not have the negative criticism that we did with (1), which led us to provide a reason for $\left({ }^{*}\right)$. Does anyone outside the logic classroom ever construct arguments like (2)? Since (2) without the word "probably" is an obviously valid deductive argument, the insertion of "probably," although not logically wrong, is certainly illmotivated. One wonders whether anyone seriously reasons according to (2). It is for these reasons that in [5] I called arguments like (2) "freaks." I mention this because Englebretsen seems to take exception to this word, and, more importantly, states that one recourse open to me regarding arguments like (2) (and (1)!) is "to avoid classification all together by admitting them as recalcitrant 'freaks,"' ([2], p. 27). I vigorously reject this approach, and want to set the record straight that I never endorsed it in [5] nor said anything which could be construed as such an endorsement, should one suppose this from Englebretsen's remark. What I did say was that I failed sto see that anything really important for a classificatory system hinged on how arguments like (2) were classified. Counterintuitive results here do not constitute much evidence against $\left({ }^{*}\right)$, should we regard counting arguments like (2) inductive as counterintuitive. Nothing I have said indicates that I endorse a policy of not classifying such arguments.

Let's turn now from $\left({ }^{*}\right)$ and the precedence question to the other issue where Englebretsen finds my discussion unsatisfactory - a lack of theory explaining why some argument families are deductive and others inductive. Why is this important to the issue of distinguishing deductive from inductive arguments? Frequently arguments are presented containing no modal words. Suppose we modified (1) to read

(1') Washington was rational. Lincoln was rational.

Kennedy was rational.

So, all U.S. presidents are rational.

and (2) to read

(2') All men are rational.

All U.S. presidents are men.

So, all U.S. presidents are rational.

How would we judge whether these arguments are inductive or deductive? Clearly $\left(2^{\prime}\right)$ is deductive and we have strong reason for regarding $\left(1^{\prime}\right)$ as inductive. Note that my claim for $\left(1^{\prime}\right)$ is less categorical 
than for $\left(2^{\prime}\right)$. An inductive modality is in effect a hedge. Some philosophers and logicians might regard the absence of an inductive hedge as tantamount to making the deductive claim and would count $\left(1^{\prime}\right)$ deductive. In fact, this supposition seems to underly Alex Michalos' discussion of distinguishing deductive from inductive arguments in [9]. But we cannot go into these issues further. Granted that $\left(1^{\prime}\right)$ is inductive and $\left(2^{\prime}\right)$ deductive, what led us to make these judgments?

Here Englebretsen seems to misrepresent, and significantly misrepresent, my discussion in [5]. Englebretsen gives the impression that I regard $\left(1^{\prime}\right)^{\prime} s$ being inductive and $\left(2^{\prime}\right)^{\prime} s$ being deductive as a matter of tradition, which has somehow opaquely assigned some arguments to the inductive family and others to the deductive family. This is not my position in [5]. Here is what I did say:

\begin{abstract}
Arguments belong to families, the members of which are traditionally assessed by either deductive of inductive standards. Membership in such a family is an implicit prima facie indicator of the argument's status. On the deductive side, we may obviously cite the families of truth-functional propositional arguments, of quantificational arguments, and of mathematical arguments. On the inductive side, we have such families as inductive generalizations, analogies, causal arguments, and good-reasons arguments. Belonging to one of these families is a prima facie indicator that the argument is a deductive or inductive, depending on the family.
\end{abstract}

([5], pp. 8-9) So when I talk of argument families in this context, 1 do not mean the entire class of inductive arguments or deductive arguments, which might be regarded as super families or families of families, but rather such classes of arguments as those mentioned. We judge $\left(1^{\prime}\right)$ to be inductive because we recognize that it is an inductive generalization, a member of the inductive generalization family. We recognize it as a member of this family because of its form, a general conclusion is drawn from particular instances. We recognize $\left(2^{\prime}\right)$ as deductive because it is a categorical syllogism. We again make this judgment on the basis of form, the fact that exactly one conclusion is drawn from exactly two premises and that all component statements are categorical propositions (again a formal judgment). In neigher case, then, do we simply say that this is a matter of bald tradition. My position in [5] is that membership in such families is a prima facie mark that an argument is inductive or deductive, depending on whether the family is inductive or deductive. And when the question is just one of enumerating inductive or deductive marks, this may be sufficient.

Of course, this does raise the question why these families should be counted as deductive or inductive families, and for a theoretically complete account we should provide such a rationale beyond saying that they have been traditionally counted as such. Why then should categorical syllogisms be counted as deductive arguments? Why are hypothetical syllogisms, disjunctive syllogisms, in general the arguments studied in the deductive logic sections of logic books or in whole texts on deductive logic deductive arguments and so appropriately evaluated by deductive means? What is the deductive claim? It is that the premises, if true, guarantee that the conclusion is true; it is impossible for the premises to be true without the conclusion also being true. Now there are some categorical syllogisms-and other arguments studied in the deductive logic sections of logic books - for which this claim is obviously true, (2') above for example. In explaining why this argument is valid, as opposed to intuitively recognizing that it is valid, we point to its form, its mood and figure, AAA-I. To see why arguments of this form are valid, we look at the truth-conditions for A-categorical propositions. Whenever those truth conditions are satisfied for both premises, the conclusion must be true also. We can see why other categorical syllogisms are not valid by again looking at their form, which permits construction of counterexamples, showing that the deductive claim does not hold for arguments of this form. By virtue of displaying these formal features, features by virtue of which we may identify the mood and figure of a categorical syllogism, we may identify an argument as a categorical syllogism, as a member of this family or sub-family of quantificational arguments. And it is by virtue of these features that we can test or judge members of this family to be deductively valid or invalid. Therefore the family of categorical syllogisms is a deductive family and recognizing an argument as a member of this family is sufficient to correctly classify it as a deductive argument. Analogous arguments could be presented for other families of deductive arguments.

Similar reasoning justifies calling the traditional inductive families or arguments inductive families. Let's consider the simplest case, the family of inductive generalizations, of which $\left(1^{\prime}\right)$ is a member. Why should this be an inductive family? What is the inductive claim? It is that the premises give some support, but not necessarily conclusive support, to the conclusion. We judge an argument to be an inductive generalization by means of its form.

(1) $e_{1}$ is an $\mathbf{A}$ and $a \mathbf{B}$.

(2) ez is an $\mathbf{A}$ and a $\mathbf{B}$.

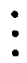

(n) en is an $\mathbf{A}$ and a $\mathbf{B}$. Therefore $(n+1)$ All $\mathbf{A}^{\prime}$ s are $\mathbf{B}^{\prime} \mathbf{s}$.

This is the standard pattern, admitting some variations which we need not consider here. But just by inspecting this pattern, we can see why arguments of this form satisfy the inductive claim. By presenting a number of instances of a universal generalization, I have presented evidence for that generalization, 
although not conclusive evidence for it. Hence, it is appropriate to count the family of inductive generalization arguments as an inductive family and to judge an argument inductive when recognizing that it is a member of this family. Similar arguments could be provided for the other inductive families. These considerations, then, provide a rationale, a theoretical backing for saying that the argument families traditionally regarded as deductive are deductive argument familes, and those traditionally regarded as inductive are inductive argument families.

In this connection, we should comment on Englebretsen's suggestion for distinguishing deductive and inductive arguments. Englebretsen begins by asserting that the central concern of formal or deductive logic is with entailment. At the risk of sounding nit-picking, I want to voice an objection right at this point. Entailment is a central logical concept, but there are others-logical truth, logical falsehood, consistency, inconsistency. In particular, and this is why this objection is not nit-picking, entailment and validity are two closely related but different concepts. We may ask of any set of statements whether or not it entails a given statement. When we ask whether an argument is valid, we ask of its set of premises, statements specifically designated as having a certain argumentative role, whether they entail the conclusion, a statement also with a specifically designated argumentative role. (Compare Leblanc and Wisdom, [8], pp. 1-5, 39, 155.) Confusion of entailment and validity occurs throughout Englebretsen's discussion here, and it vitiates his suggestion as a constructive proposal. We shall see how.

Englebretsen continues his discussion, "The formal logician (qua deductive logician) takes all entailments as purported deductions and judges them accordingly" ([2], p. 27). I find this sentence confusing. What does it mean to take an entailment as a purported deduction? I can think of at least three interpretations. It could mean that the formal logician takes all arguments as deductive arguments and judges them accordingly. But is that true as an empirical claim? Do deductive logicians actually go about trying to construct derivations or produce counterexamples to show that all inductive generalizations, causal arguments, arguments by analogy they may consider are deductively valid or invalid? From the context, this seems to be what Englebretsen means by judging arguments. Or do deductive logicians simply recognize these arguments as inductive, requiring other means of evaluation? Or does just the recognizing that the argument belongs to an inductive family constitute the judging?

What about the other two interpretations? Entailment is a relation which may or may not hold between a set of statements $\mathbf{S}$ and a given statement
A. The relation holds when it is not possible for all the members of $\mathbf{S}$ to be true together and $\mathbf{A}$ false. We have an entailment, then, just when this relation holds. The second interpretation understands "entailment" in just this sense. An entailment is an actual instance of the entailment relation. But what does it mean to take an entailment in this sense as a purported deduction and judge it accordingly? I for one do not understand the question. But I do not think this is the sense of "entailment" that Englebretsen is using in this sentence. Rather, and this is the third interpretation, by "entailment" I believe he may mean any order pair $\langle\mathbf{S}, \mathbf{A}\rangle$ where $\mathbf{S}$ is a set (possibly empty) of statements and $\mathbf{A}$ is a statement. But what is a purported deduction? Indeed, what is a deduction? Is a deduction an instance of the entailment relation? This may be Englebretsen's meaning here. Purported deductions could then be tested to see whether they were genuine instances of the entailment relation, entailments in the second sense defined above. Similarly, the pairs $\langle\mathbf{S}, \mathbf{A}\rangle$ could also be tested to see whether they were genuine instances of inductive support.

If this is indeed Englebretsen's meaning, or one of his meanings, and the remainder of the passage gives warrant for this interpretation, then as long as he holds to this meaning, Englebretsen has shifted "deduction" (and "induction") from being categories applied to arguments to being categories applied to semantic relations between sets of statements and statements (and methods for evaluating such relations). But these are two different things, as we have explained above. To appreciate the magnitude of this change, I want to suggest that although it may be straightforward to explicitly define when semantic relations are deductive or inductive along the lines of Englebretsen's discussion, it is not at all obvious how the notions of deductive and inductive arguments could be defined in terms of this definition in a way the inductive/deductive distinction has been ordinarily understood to holddividing the entire class or arguments into two mutually exclusive subclasses, with both valid and invalid members of each subclass. Here is how one might give an explicit definition of "deductive" and "inductive" for semantic relations:

An entailment (third interpretation) $\langle\mathbf{S}, \mathbf{A}\rangle$ is deductive or a deduction just in case $\mathbf{S}$ entails $A$, i.e. all the members of $\mathbf{S}$ cannot be true and A false.

An entailment $\langle\mathbf{S}, \mathbf{A}\rangle$ is inductive or an induction just in case $\mathbf{S}$ supports $\mathbf{A}$ to some degree but does not entail it.

Note that I am not claiming these are the definitions Englebretsen would give. He does not spell out a precise ineaning of these concepts in his paper. One might then define deductive and inductive argu- 
ments in terms of deductive and inductive entailments as follows:

An argument from premises $\left\{\mathbf{A}_{1}, \mathbf{A}_{2}, \ldots, \mathbf{A}_{n}\right\}$ to conclusion $B$ is deductive just in case $\left\langle\left\{\mathbf{A}_{1}, \mathbf{A}_{2}\right.\right.$, $\left.\left.\ldots, A_{n}\right\} \mathbf{B}\right\rangle$ is a deduction; it is inductive just in case $\left\langle\left\{\mathbf{A}_{1}, \mathbf{A}_{2}, \ldots, \mathbf{A}_{n}\right\}, \mathbf{B}\right\rangle$ is an induction.

But such a definition is at serious variance with the deductive/inductive distinction as ordinarily understood for arguments. For according to this definition, there can be no invalid deductive arguments. If the premises of an argument fail to entail (second sense) the conclusion, then either the argument is inductive or it ends up, along with perhaps some other arguments, in some limbo category. Is it true that any set of statements $\mathbf{S}$ gives some support, however minimal, to an arbitrary sentence $\mathbf{A}$ ? In particular, do the premises of any invalid deductive argument give some support to the conclusion? If not, then according to our definition, some arguments will fail to be either deductive or inductive.

Let me again emphasize that these are not Englebretsen's definitions. We should not attribute them to him. Indeed, there is another way of interpreting the passage rather different from those suggested above. Englebretsen mav be advocating that we define "deductively valid," "deductively invalid," "inductively valid," "inductively invalid" for arguments and leave it at that. His discussion stresses these notions. But this does not address the question of when arguments are deductive or inductive. That is another question again. I do not know whether Englebretsen wants to leave it at that. I suspect not. The problem is, as I have suggested above, that there is genuine confusion in this proposal of the question of when arguments are deductive or inductive, deductively or inductively valid or invalid, and when semantic relations of entailment or inductive support hold. Indeed, this confusion is highlighted in the following quote:

Suppose I find a piece of paper with the sentence

1) All men are rational.

writen on it. At some other time (earlier or later) I hear on the radio

2) All U.S. presidents are men.

And at some other time still I read on my classroom blackboard

\section{3) All U.S. presidents are rational.}

I would be a poor logician not to recognize that 1 and 2 jointly entail 3 ... Yet $I$ judge these sentences to constitute a (valid) deductive argument. ([2], p. 27)
This last sentence is just plain wrong. $\{1,2\}$ entail 3 , i.e. the semantic relation of entailment holds between $\{1,2\}$ and 3 . Yet there is no deductively valid argument here because there is no argument to begin with! An argument is not just a set of statements. At the least, a specific statement must be designated or intended as the conclusion. And we do not have that in the above example. If Englebretsen wishes the deduction/induction distinction to apply to arguments, he should specifically and explicitly define it as such. If he wants it to apply just to certain semantic relations, he should explicitly define it as such. But if so, he should recognize and admit that he has changed the meaning of the inductive/deductive distinction significantly. If he wants to define only the expressions "deductively valid," "deductively invalid," "inductively valid," "inductively invalid," he should do so. But again he should recognize and admit that he is not trying to distinguish deductive from inductive arguments.

Now perhaps there are reasons for wanting the deduction/induction distinction to apply not to arguments but to something else. There has been discussion in the pages of the Informal Logic Newsletter on whether inductive and deductive should be used to classify types of validity rather than types or arguments, David Hitchcock leading the challenge. (See [6].) We cannot go into these issues here. Let me, however, give one reason why deduction and induction should be used to classify arguments. It is a commonplace that arguments are frequently stated incompletely. Indeed, supplying suppressed premises is a central topic in informal logic courses. When supplying a suppressed premise, there are two considerations to keep in mind. First, in a broad sense of logical including deductive and inductive concerns, the supplied premise must be logically needed if the argument is to be correct. On the other hand, the supplied premise must be used by the arguer. To the extent that we can determine the intentions of the person putting forward the argument, our supplied premise must be in accord with those intentions. In [3], Robert Ennis discusses needed and used assumptions in much greater detail. This gives us two guidelines for considering candidates for supplied premise. First, the candidate must be strong enough to produce a logically correct argument when added to the premises manifestly stated. Secondly, the candidate premise must not be stronger than what the arguer would accept.

How does this bear on the inductive/deductive distinction? Consider the following two arguments:

(3) All Senators are politicians, so All Senators are amoral.

(4) Alice is dressed to kill, so I expect that she is ready for a big date. 
Both of these arguments involve suppressed premises. In both cases, we could ask why the given premise is relevant to the conclusion. In each case, the premise to be supplied should function to make plain why the manifestly state premise is relevant to the conclusion. Again in each case, we can conceive of at least two candidates to explain his relevance. Adding either

\section{(a) All politicians are amoral}

or

(b) Most politicians are amoral

gives us a set of premises relevant to the conclusion. But 1 expect we all would regard the first as the correct premise to add, barring contextual evidence to the contrary. Why? Adding (a) produces a deductively valid argument. Adding (b) produces one which gives at least some support to the conclusion. We choose (a) because we recognize that (3) is an incompletely stated categorical syllogism and so a deductive argument, and (a) produces a deductivelv correct argument. Hence, recognizing (3) as a deductive argument was a distinct factor in the process of identifying the proper suppressed premise to add.

Now consider (4). Again two candidate premises readily come to mind:

(c) Whenever anyone is dressed to kill, that person is going out on a big date.

(d) Frequently when someone is dressed to kill, that person is ready for a big date.

Here the second premise seems obviously the correct one to add, again barring contrary contextual evidence. Why? Both candidates explain why the manifestly stated premise is relevant to the conclusion. Adding (c) produces a deductively valid argument. Adding (d) produces an inductively plausible argument. We regard (d) as correct because given the presence of the madality "I expect that" and perhaps other factors, we judge (4) to be an inductive argument. Hence we do not need a statement as strong as (c) to produce a correct argument. Furthermore (c) is clearly false. Hence, unless there were sufficient evidence to the contrary, it would be wrong to attribute it to whomever propounds (4). Therefore, we see that judging whether arguments are deductive or inductive is a distinct step in the process of supplying suppressed premises. This is one reason for regarding the inductive/deductive distinction as applying to arguments.

To sum up, in this reply I have answered both criticisms Englebretsen has brought against me in [2]. As in [5], 1 have put the precedence criterion in perspective and given a defense of it, although here the defense is developed further. I have filled the theoretical gap Englebretsen calls attention to, explaining why deductive and inductive argument families are families of deductive or inductive arguments. I find that Englebretsen's account of what I say in [5] is sometimes in error and sometimes significantly misrepresents or distorts my position in [5]. In addition, he sometimes makes dubious empirical claims. I have examined Englebretseñ's suggestion for distinguishing deductive and inductive arguments and have argued that it is deeply flawed. It does, however, raise the question of whether "inductive" and "deductive" should be properties of arguments or of something else. I have concluded with an argument that the traditional view, regarding induction and deduction as types of arguments, has some justification.

\section{Bibliography}

[1] Copi, Irving. Introduction to Logic Sixth Edition. New York; Macmillan Publishing Company, Inc., 1982.

[2]Englebretsen, George. "Freeman on Deduction/ Induction." Informal Logic vi. 1 (1984), 26-27.

[3] Ennis, Robert H. "Identifying Implicit Assumptions." Synthese 51 (1982), 61-86.

[4] Fohr, Samuel D. "Deductive-Inductive: Reply to Criticism." Informal Logic Newsletter iii.1 (1980), 5-10.

[5] Freeman, James B. "Logical Form, Probability Interpretations, and the Inductive/Deductive Distinction." Informal Logic Newsletter v.2 (1983), 2-10.

[6] Hitchcock, David. "Deductive and Inductive: Types of Validity, Not Types or Argument." Informal Logic Newsletter iii.3 (1980), 4-5.

[8] Leblanc, Hugues and Wisdom, William A. Deductive Logic Second Edition. Boston, Allyn and Bacon, Inc., 1976.

[9] Michalos, Alex C. Improving Your Reasoning. Englewood Cliffs, N. J .; Prentice-Hall, Inc., 1970.

[10] Weddle, Perry, "Good Grief! More on Deduction/Induction." Informal Logic Newsletter iii.1 (1980), 10-13.

[11] _Inductive, Deductive." Informal Logic Newsletter ii.1 (1979), 1-5. $\square$

Professor James B. Freman, Department of Philosophy, Hunter College, 695 Park Avenue, New York, N.Y. 10021. 


\section{Reply to Fred Johnson}

\section{G.A. Spangler}

\section{California State University Long Beach}

I agree with Fred Johnson in (1) that there is a distinction to be drawn between someone's giving us an argument and the argument we are given. My position in (2) presupposes that if someone presents an argument, then there is some argument presented. But I was arguing there that, though arguings and arguments are distinguishable, they are not separable in the way that Fogelin's treatment of then in (3) sometimes suggest.

Johnson proposes that arguments should be seen as "passive sets of statements connected in various ways" rather than as "active entities that intend to have parts that present." This, however, is a bogus contrast, despite our common practice of speaking of instruments as though they had properties of their employers and makers. When we say of an argument that, e.g., "its primary intention is to establish S," we are not acting like the person Johnson imagines saying of a car that it is ill and needs to see a doctor. We are rather more like the person who asks of a tool in a toolbox, "And what does this one do?" Someone who doesn't know what a car is (who might this be?) may, as Johnson suggests, be seriously misled if he is told that cars feel ill and want to go to doctors (who would say this in such a circumstance?), but a college student will not be misled in this unlikely way by a teacher or a text that speaks (sic) of the intention of an argument, any more that he or she would by speaking of the purpose of a billy club.

Johnson proposes that we adopt a metaphysically neutral way of defining "argument" in informal logic courses, but 1 find no such definition in his paper. He cautions that we should resist the temptation to define "argument" as "an ordered pair whose first member is a set of propositions and whose second number is a proposition" on the grounds that such a move may land us in complicated realist/nominalist disputes but he doesn't spell out why we might be so tempted. I would object to this definition on the grounds that it does not help us to distinguish arguments from certain lists, petitions or, even, prayers. His own proposal is that we adopt an "ostensive method" because by means of it "we can have the most success in helping our students recognize arguments." But, without rehearsing familiar Socratic objections to this practice, I want to contend that in so acting we would not be doing enough.

I don't think that anyone would deny that pointing out examples of arguments is a good way to help students to recognize them. But in getting students into a position to recognize arguments we are facing a task akin to a parent's who wants his or her child to learn how to recognize potential molesters. The child has been led astray who asks, "What does a molester look like?"' Arguments, like molesters, are hidden by contexts rather than by strange appearances. Knowing that an argument is a set of propositions connected in various ways is like knowing that a molester is a person with certain intentions.

The students in our informal logic classes are familiar with the intentions and purposes of the arguer in a way that the child is not acquainted with the motives and desires of one who would do it harm. Our students are arguers, and they know what it is like to try to establish the truth of something or to build a convincing case for something. So instead of asking whether there is an argument in, say, a newspaper editorial, we can ask whether the editorial writer is arguing for something in an editorial. Of what is the author trying to convince us in the piece (if anything)? This is his conclusion, etc. By understanding arguments through the arguer's purposes, we are provided with a means for recognizing the alien ("argument" is a quasi-technical term) through the familiar (arguing is a common, human practice). One of the many virtues of Fogelin's book is its attempt to locate the criticism of arguments in the wider, familiar context of criticizing discourse, and showing that there are ways of criticizing arguments besides noting their invalidity.

At some point in a course in informal logic it may be useful to speak of arguments as sets of statements. If something of the form, "p since $q, "$ is 
pointed out, then what is pointed out is a set of statements. But since some such sets are not arguments, it cannot be concluded that an argument is (= can be defined as) a set of statements. For certain purposes, of course, it may be helpful to speak in this way, just as for some purposes it may be useful to speak of automobiles as collections of parts. My criticism of Fogelin was not motivated so much by metaphysical considerations as considerations of pedagogy. The arguer is in the foreground, together with his purposes, in the first two chapters of Understanding Arguments, and then drops out of the picture in the third chapter on arguments.

I thus have no objection to Johnson's point that "if that $\mathbf{A}$ since $\mathbf{B}$ is an argument then it could be the case that that A since B is also an explanation." My objection is to the way in which the point is put. I prefer to say that an argument may serve as an explanation or to explain something. Similarly, I would say that what is here functioning as a premise may there serve as a conclusion. From this it does not follow that premises are conclusions any more than it does that arguments are explanations. Indeed, my principle point is that keeping the arguer and his purposes in view helps to keep such distinctions clear.

\section{Notes}

(1) Johnson, Fred, "Arguings and Arguments," Informal Logic Newsletter, (1984) 26-27.

(2) Spangler, G.A., 'Fogelin's Understanding Arguments", Informal Logic Newsletter, v. 2 (1983), 27-30.

(3) Fogelin, Robert J., Understanding Arguments, 2nd edition, (New York: Harcourt Brace Jovanovich 1982).

Prof. G.A. Spangler, Department of Philosophy, California State University Long Beach, Long Beach, CA. 90840.

\section{McPeck on Critical Thinking: A Reply}

\section{David B. Annis Linda F. Annis}

\section{Ball State University}

In a recent article, John McPeck criticizes much of the work which has been done on critical thinking! He used our published work as "an excellent example of some confusions which underlie much of educational literature in general and the critical thinking evaluations literature in particular."2 McPeck seriously misrepresents our views. We wish to set the record straight. In so doing, we shall also reply to several of his general claims about the research on critical thinking.

\section{Critical Thinking Abilities}

McPeck attacks those who claim that critical thinking can be identified with a set of abilities such as the ability to draw valid conclusions, to recognize unstated but implicit premises, to evaluate evidence, etc. Such researchers have failed to prove the existence of these abilities. What has happened is that they have taken the description of an achievement ( $\mathbf{S}$ can draw valid conclusions) and inferred that there was an underlying ability corresponding to the description. But it does not follow that there is a corresponding unitary ability. Many separate abilities may be involves "or conversely, nothing recognizable as an ability might have been involved."3

Consider the ability to draw valid conclusions. If $S$ can draw valid conclusions (an achievement), we may infer $\mathbf{S}$ has the ability to do this. (If $\mathbf{S}$ can do $\mathbf{X}$, then $\mathbf{S}$ is able to do $\mathbf{X}$. If $\mathbf{S}$ is able to do $\mathbf{X}, \mathbf{S}$ has the ability to do $X$.) What does not follow of course is that the ability to do $\mathbf{X}$ is not composed of other abilities. It may be that the ability to draw valid conclusions consists of a number of abilities. This, however, is not inconsistent with identifying critical 
thinking with a set of abilities such as the ability to draw valid conclusions. It simply means that the ability to draw valid conclusions involves a number of other things. Those who wish to identify critical thinking with a set of abilities such as evaluating evidence, recognizing unstated premises, etc. are not committed to the thesis that these abilities are not composed of other abilities.

\section{The definition of Critical Thinking}

McPeck argues that the evaluation of critical thinking is not just an empirical question. There are different definitions of critical thinking and different criteria for measuring critical thinking. Hence it is not merely an empirical issue as to which view of critical thinking is correct. According to McPeck, critical thinking has little or nothing to do with performance on standardized critical thinking tests which attempt to measure the abilities to draw valid conclusions, identify unstated but implicit premises, etc. "(T)here is no denumerable set of skills which demarcates critical thinking, so no single test could ever hope to capture it." 4

The concept of critical thinking is certainly openended. It may be a family resemblance term. But it is hard to believe that our understanding of critical thinking is so diffuse that we cannot agree that certain types of activities are relevant to it. Researchers have consistently identified drawing valid conclusions, identifying fallacies, recognizing unstated premises, etc. as being relevant to critical thinking. No researcher to our knowledge has claimed that these abilities exhaust the concept of critical thinking. It may be true that there is no set of denumerable abilities which demarcates the concept, and perhaps no one test is adequate. But this is not a sufficient justification to reject a person's performance on such tests as the Watson-Claser Critical Thinking Appraisal or the Cornell Critical Thinking Test as irrelevant to critical thinking. Nor is it an adequate reason for claiming that such abilities as drawing valid conclusions are irrelevant to critical thinking.

\section{Tests and Measurement}

McPeck accuses us and others who have sought to test empirically the impact that different courses or programs have on critical thinking of:

(a) assuming that for something to be empirically known, it must be test measurable; and

(b) assuming that the sole purpose of education is to develop skills, and hence that the value of a subject maiter is only instrumental.

We make neither of these assumptions.

There are all sorts of things people know empirically which are not known on the basis of statistical tests, e.g., that one is having a certain sensation, that one is seeing a barn, that Lincoln was the 16th President, etc. Consider now the claim (C) that a certain course does improve critical thinking. What this statement $\mathbf{C}$ implies is that:

(i) there was improvement; and

(ii) the course caused the improvement; it was not due simply to other factors.

(This is true even if we define critical thinking in the way McPeck does, and even if critical thinking is field-dependent.) McPeck claims that we can know a course or program improves critical thinking on the basis of "direct inspection."

We do not wish to claim that it is not possible to know casual hypotheses such as $\mathbf{C}$ independently of statistical evidence. If someone were consistently right about causal hypotheses and their claims were not based on the usual kind of experiments, we might conclude that the person knew the truth of the causal claims. (Consider the savant and the seer cases discussed in the philosophical literature.) But, in general, it is hard to understand how one could know such causal hypotheses by direct inspection. How does one directly inspect that the improvement was not caused by other factors? Think of the controversy surrounding the relationship of saccharin and cancer, tobacco and cancer, or blood clots and the pill. ${ }^{5}$ It took numerous statistical experiments and great expense to begin to establish these relationships. Hence we would argue that for one to know a causal hypotheses is true, in general it must be based on statistical evidence.

Consider the second assumption McPeck claims that researchers on critical thinking make. If one attempts to determine what impact a program has, it certainly does not follow that the researcher assumes the program only has instrumental value. In the case of our research, various philosophers as well as the American Philosophical Association had claimed that the study of philosophy improves critical thinking. No evidence was given in support of this causal hypothesis. Hence we sought to test empirically this causal claim. ${ }^{\text {This }}$ is not at all inconsistent with saying that philosophy has intrinsic value as well.

In summary, researchers on critical thinking do not necessarily make the assumptions McPeck attributes to them. Furthermore much of the major work on critical thinking is consistent with many of the arguments McPeck gives 8 


\section{Notes}

1 John McPeck, "The Evaluation of Critical Thinking Programs: Dangers and Dogmas," Informal Logic, 6:2 (July), 1984:9-13.

2 lbid., p. 11

3/bid., p. 10

4 Ibid., p. 11.

5 For an analysis of causal hypotheses and a discussion of these examples, see Ronald N. Giere, Understanding Scientific Reasoning (N.Y.: Holt, Rinehart and Winston, 1979), Ch. 12.

6 David Annis, Linda Annis, "Does Philosophy Improve Critical Thinking?," Teaching Philosophy, 3:2 (Fall), 1979:145-152. 7lt should be noted, however, that it is not exactly clear what it means to say that philosophy is intrinsically valuable or whether the statement is true. See, e.g., William Frankena's discussion of intrinsic value in his Ethics, 2nd ed. (Englewood, N. J .: Prentice-Hall, 1973) Ch.5.

8We wish to thank Professor Arnold Wilson, the Editor of Teaching Philosophy, for making us aware of McPeck's article. Professor Wilson attended the Second International Symposium on Informal Logic Held at the University of Windsor in June 1983 when McPeck presented his paper.

Dr. David B. Annis and Dr. Linda F. Annis, Department of Philosphy, Ball State University, Muncie, IN 47306.

\section{note}

\section{Informal Logic in China}

\section{John Nolt}

\section{University of Tennessee}

There is, in The People's Republic of China, great potential for interest in and development of informal logic. That is my impression from recent discussions with students and faculty members at Nanjing Institute of Technology. I had gone to China primarily as a tourist, but from July 20 to July 24, 1984, I was a guest at the Institute, where I gave a talk outlining the development in informal logic in the U.S. and Canada.
I had not known what to expect, having relatively little information on the status of logic in China. I hoped to learn at least as much as I had to tell. What $\mid$ found was an electrifying cosmopolitanism among the young and a lingering dogmatism among the older generation.

Before the communist victory in 1949, China harbored a large school of Vienna-style logical pos- 